\title{
Effects of intermittently scanned continuous glucose monitoring on blood glucose control and the production of urinary ketone bodies in pregestational diabetes mellitus
}

Shu-ying Li ${ }^{1,2}$, Hang Guo ${ }^{2}$, Yi Zhang ${ }^{2}$, Pei Li ${ }^{2}$, Pei Zhou ${ }^{2}$, Li-rong Sun ${ }^{2}$, Jing Li ${ }^{2}$ and Li-ming Chen ${ }^{2 *}$

\begin{abstract}
Objective: To investigate the effects of intermittently scanned continuous glucose monitoring (isCGM) on blood glucose control, clinical value of blood glucose monitoring and production of urinary ketone bodies in pregestational diabetes mellitus.

Method: A total of 124 patients with pregestational diabetes mellitus at 12-14 weeks of gestation admitted to the gestational diabetes clinic of our hospital from December 2016 to December 2018 were selected and randomly divided into two groups. Sixty patients adopted self-monitoring of blood glucose (SMBG) were taken as the control group, and the other 64 patients adopted isCGM system by wearing the device for 14 days. Blood sugar control, glycosylated albumin level, ketone production in urine, the maximum and minimum of blood sugar value measured by different monitoring methods and their occurrence time were observed in the two groups.

Result: (1) No statistically significant differences were found between the groups in terms of maternal age, gestational age at first visit, family history, duration of diabetes, education level, total insulin dose, chronic hypertension, abortion history, nulliparity, assisted reproductive technology, history of macrosomia childbirth, pre-pregnancy BMI, and overweight (\%) at the first visit and hypoglycemia, (2) the value of Glycated Albumin was lower in the CGM group compared to the control group at 2ed weeks (14.6 \pm 2.2 vs. $16.8 \pm 2.7, p<0.001)$. The women in the CGM group spent increased time in the recommended glucose control target range of $3.5-7.8 \mathrm{mmol} / \mathrm{L}(69 \pm 10 \% \mathrm{vs} .62 \pm 11 \%$, $p<0.001)$ and reduced time above target compared with those in the control group at 2 weeks $(25 \pm 7 \% \mathrm{vs} .31 \pm 8 \%$, $\mathrm{p}<0.001)$. In the second week of the study, the positive rate of urinary ketone body in isCGM group was lower than that in the control group ( $42 \pm 5 \mathrm{vs} .54 \pm 5, \mathrm{p}<0.001)$, and (3) the minimum blood glucose of $31.2 \%(20 / 64)$ cases in isCGM group appeared during 0:00-2:59 at night, and 26.6\% (17/64) cases appeared during 3:00-5:59 at night. The minimum values of $40.0 \%$ (24/60) cases in the control group appeared within the $30 \mathrm{~min}$ before lunch, 23.3\% (14/60) within the 30 min before breakfast, and $11.7 \%(7 / 60)$ within the 30 min before dinner. The cases of minimum of blood sugar before meals accounted for $75 \%$ of all the minimum values, and the cases of minimum at night only accounted for $8.3 \%$.
\end{abstract}

\footnotetext{
*Correspondence: xfx22081@vip.163.com

${ }^{2}$ NHC Key Laboratory of Hormones and Development (Tianjin Medical University), Tianjin Key Laboratory of Metabolic Diseases, Tianjin

Medical University Chu Hsien-I Memorial Hospital \& Tianjin Institute of Endocrinology, Tianjin 300134, China

Full list of author information is available at the end of the article
}

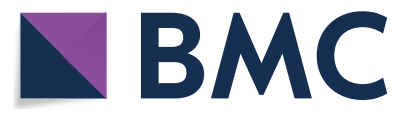

(c) The Author(s) 2021. This article is licensed under a Creative Commons Attribution 4.0 International License, which permits use, sharing, adaptation, distribution and reproduction in any medium or format, as long as you give appropriate credit to the original author(s) and the source, provide a link to the Creative Commons licence, and indicate if changes were made. The images or other third party material in this article are included in the article's Creative Commons licence, unless indicated otherwise in a credit line to the material. If material is not included in the article's Creative Commons licence and your intended use is not permitted by statutory regulation or exceeds the permitted use, you will need to obtain permission directly from the copyright holder. To view a copy of this licence, visit http://creativeco mmons.org/licenses/by/4.0/. The Creative Commons Public Domain Dedication waiver (http://creativecommons.org/publicdomain/ zero/1.0/) applies to the data made available in this article, unless otherwise stated in a credit line to the data. 
Conclusion: Intermittently scanned continuous glucose monitoring can reduce hyperglycemia exposure and ketone body formation in pregestational diabetes mellitus. In addition, isCGM is better than SMBG in detecting nocturnal hypoglycemia.

Keywords: Pregestational diabetes mellitus, Intermittently scanned continuous glucose monitoring, Blood glucose control

\section{Introduction}

With the increasing prevalence of obesity, type 2 diabetes mellitus has become the most common disease among women of childbearing age [1]. The International Diabetes Federation (IDF) estimated that 21.3 million (16.2\%) live births were delivered from women with hyperglycaemia in pregnancy (HIP) in 2017. Among them, gestational diabetes mellitus (GDM) accounted for $86.4 \%$, pregestational diabetes mellitus (PGDM) accounted for $6.2 \%$, and other types of diabetes (including type 1 and type 2 diabetes) found for the first time during pregnancy accounted for 7.4\% [2]. Surveillance of chronic diseases and their risk factors in China in 2013 showed that the prevalence of adult diabetes was $10.9 \%$ [3], and in recent years, the incidence age of type 2 diabetes mellitus has gradually decreased. Thus, an increasingly larger number of women can be expected to have type 2 diabetes mellitus and its complications during pregnancy. In the mother, poor glycemic control during pregnancy can increase ketone body formation, cause abortion and fetal arrest, and lead to the need for a cesarean section due to fetal macrosomia [4]. In the infant, a major concern is hypoglycemia after birth. Poor glycemic control in pregnancy has even been shown to be related to the intelligence of offspring $[5,6]$. Therefore, it is very important to control blood glucose during pregnancy.

Dynamic blood glucose monitoring is a technique that uses a glucose sensor to monitor the glucose concentration of subcutaneous interstitial fluid, thus indirectly reflecting the blood glucose level. Intermittently scanned continuous glucose monitoring (isCGM) can display the instant blood glucose as well as the blood glucose fluctuations from the entire day, and through an alarm system, it can notify the user about abnormal blood glucose levels at the current time or in the future. This increases the timeliness of insulin dose adjustment and hypoglycemia correction. In contrast, traditional SMBG can only reflect static and instantaneous blood glucose, and it is easy to omit concealed hypoglycemia and hyperglycemia, so it cannot comprehensively evaluate the changes of blood sugar [7]. Previous studies have primarily focused on the impact of dynamic blood glucose monitoring on blood glucose and pregnancy outcomes in pregnant patients with type 1 diabetes mellitus $[8,9]$, while the impact of this on blood glucose control and ketosis in pregnant patients with type 2 diabetes mellitus is rarely studied. Therefore, our study evaluates the outcomes of the two different monitoring methods, isCGM and SMBG, on blood glucose monitoring, blood glucose control, and ketosis in pregestational diabetes mellitus.

\section{Subjects and methods Subjects}

A randomized controlled study was conducted on all pregnant patients at 12-14 weeks gestation with type 2 diabetes mellitus in our hospital from December 2016 to December 2018. Inclusion criteria was age between 21 and 40 years old, singleton gestation, and need for multiple insulin injections daily. The included participants also had to be skilled in using smartphones and willing to cooperate and follow-up regularly. Patients with multiple pregnancies and serious comorbid conditions were excluded. Additionally, patients with hyperemesis gravidarum were excluded. The purpose and significance of the study was explained to the subjects, their consent was obtained, and informed consent was signed. The study was approved by the Ethics Committee of Metabolic Disease Hospital of Tianjin Medical University (No. DXBYYhMEC2016-21).

\section{Methods}

Patients were randomly divided into two groups using the Excel table random sampling method. The control group used SMBG to monitor blood glucose $(n=60)$; the isCGM group used intermittently scanned continuous glucose monitoring system to monitor blood glucose $(\mathrm{n}=64)$.

Patients in the control group were monitored by SMBG. Blood glucose in capillaries was monitored eight times a day (before meals and $2 \mathrm{~h}$ after meals, before going to bed, and at midnight). Patients download the Dnurse App (Beijing Dnurse Technology Co., Ltd) in which they used the Outpatient mode. Fasting and postprandial glucose self-measurements could be monitored using the Dnurse blood glucose meter (automatic data upload or manual data upload). Blood glucose data were compiled into tables and charts that were then uploaded and transmitted to the Doctor,s version of Dnurse App. IsCGM group patients were monitored by isCGM (FreeStyle Libre, Abbott). At the first visit, a professional 
diabetes nurse provided the patient with one-on-one equipment installation and system maintenance training. The glucose sensor was placed on the patient's upper arm. The system automatically recorded the blood sugar value of the interstitial fluid every $15 \mathrm{~min}$. In addition, glucose readings and glucose trends were obtained by scanning the sensor with a scanning detector. Patients wore the device for a total of 14 days, during which blood sugar values were uploaded through the diabetes management APP.

All patients personalized dietary guidance by an educational nurse during a patient's first visit. This nurse calculates the amount of protein, fat, and carbohydrates the patient needs daily based on their weight and activity level, develops a training plan, helps patients choose appropriate aerobic exercise, and checks their diet and exercise performance on a return visit. The specialist established the outpatient medical service file for each patient in order to record data for each visit, including blood glucose and weight, which can help with disease assessment and treatment planning. Patients were expected to see the physician once a week for 3 weeks. At each visit, the doctor adjusted the dose of insulin according to patient's blood glucose. Every days during the study period, educational nurse provided APP online guidance by answering patients' questions, such as questions related to diet, exercise, blood sugar monitoring, insulin injection. Patients' blood glucose meters were required to regularly undergo comparisons with hospital laboratory blood glucose meters (Biosen C-Line Blood Glucose Analyzer, EKF, Germany) to correct for any testing error.
In both groups, urine ketone bodies were measured every morning and $4 \mathrm{pm}$, Urine ketone body test paper is distributed uniformly by educational nurse. The fasting target blood sugar range was $3.5-5.3 \mathrm{mmol} / \mathrm{L}$, and the target range after a meal was $4.4-7.8 \mathrm{mmol} / \mathrm{L}$.

\section{Statistical methods}

Statistical analysis was performed using SPSS11.5 statistical software. The measurement data conforming to the normal distribution were expressed as $\overline{\mathrm{x}} \pm \mathrm{s}$. A $t$-test was used to compare the mean of the two groups, and a $X^{2}$ test was used to compare the constituent ratio of the two groups. A p-value $<0.05$ was considered statistically significant.

\section{Results}

\section{Control group included 60 patient and isCGM group included 64 patients}

No statistically significant differences were found between the groups in terms of maternal age, gestational age at first visit, family history, duration of diabetes, education level, total insulin dose, chronic hypertension, abortion history, nulliparity, assisted reproductive technology, history of macrosomia childbirth, pre-pregnancy BMI, overweight at first visit and hypoglycemia. $(p>0.05)$ (see Table 1).

\section{The glycemic control characteristics and ketonuria of the study groups are shown in Table 2}

The value of Glycated Albumin was lower in the isCGM group compared to the control group at 2ed

Table 1 Maternal baseline characteristics of the study groups

\begin{tabular}{llll}
\hline & Control group $(\mathrm{n}=60)$ & isCGM group $(\mathrm{n}=64)$ & $p$-value \\
\hline Maternal age (years) & $30.6 \pm 3.1$ & $31.2 \pm 4.1$ & 0.604 \\
Gestational age at first visit (w) & $9.4 \pm 2.9$ & $9.5 \pm 2.5$ & 0.726 \\
Family history of DM, $\mathrm{n}(\%)$ & $21(35.0)$ & $23(35.9)$ & 0.732 \\
Duration of diabetes (years) & $5.2 \pm 1.4$ & $4.9 \pm 1.2$ & 0.728 \\
University and above, $\mathrm{n}(\%)$ & $34(56.7)$ & $36(56.2)$ & $3(4.7)$ \\
Severe hypoglycaemia in past year, $\mathrm{n}(\%)$ & $2(3.3)$ & $0.65 \pm 0.13$ & 0.823 \\
Total insulin dose (U/kg per day) & $0.69 \pm 0.14$ & $2(3.1)$ & 0.793 \\
Chronic hypertension, $\mathrm{n}(\%)$ & $2(3.3)$ & $12(18.7)$ & 0.743 \\
Abortion history, $\mathrm{n}(\%)$ & $11(18.3)$ & $39(60.9)$ & 0.875 \\
Nulliparity, $\mathrm{n}$ (\%) & $35(58.3)$ & $3(4.7)$ & 0.842 \\
ART, $\mathrm{n}$ (\%) & $2(3.3)$ & $8(12.5)$ & 0.732 \\
History of macrosomia childbirth, $\mathrm{n}(\%)$ & $6(10.0)$ & $25.7 \pm 3.3$ & 0.531 \\
Pre-pregnancy BMI $\left(\mathrm{kg} / \mathrm{m}^{2}\right)$ & $25.6 \pm 2.9$ & $37(57.8)$ & 0.689 \\
Overweight $(\%)$ at first visit $25 \leq \mathrm{BMI}<28$ & $35(58.3)$ & $16(25.0)$ & 0.878 \\
Obesity $(\%)$ at first visit BMl $\geq 28$ & $14(23.3)$ & 0.741 & 0.625 \\
\hline
\end{tabular}

Severe hypoglycaemia was defined as an episode requiring third-party assistance

$A R T$ assisted reproductive technology, $B M I\left(\mathrm{~kg} / \mathrm{m}^{2}\right)$ body mass index 
Table 2 The glycemic control characteristics and ketonuria of the study groups

\begin{tabular}{|c|c|c|c|}
\hline & Control group $(n=60)$ & isCGM group $(n=64)$ & $p$-value \\
\hline The value of GA at baseline (\%) & $18.6 \pm 3.5$ & $18.9 \pm 3.6$ & 0.852 \\
\hline The value of GA at 14th day (\%) & $16.8 \pm 2.7$ & $14.6 \pm 2.2$ & $<0.001$ \\
\hline The value of HbAlc at baseline (\%) & $7.1 \pm 0.3$ & $7.2 \pm 0.4$ & 0.796 \\
\hline Hypoglycaemia (\%) & $2(3.3 \%)$ & $3(4.6 \%)$ & 0.656 \\
\hline Time in target during the 1st week (3.5-7.8 mmol/L) (\%) & $54 \pm 10$ & $55 \pm 11$ & 0.703 \\
\hline Time in target during the 2ed week (3.5-7.8 $\mathrm{mmol} / \mathrm{L})(\%)$ & $62 \pm 11$ & $69 \pm 10$ & $<0.001$ \\
\hline Time $>7.8 \mathrm{mmol} / \mathrm{L}$ during the $1 \mathrm{st}$ week (\%) & $36 \pm 7$ & $35 \pm 6$ & 0.723 \\
\hline Time $>7.8 \mathrm{mmol} / \mathrm{L}$ during the 2 ed week (\%) & $31 \pm 8$ & $25 \pm 7$ & $<0.001$ \\
\hline Time $<3.5 \mathrm{mmol} / \mathrm{L}$ during the $1 \mathrm{st}$ week (\%) & $8 \pm 3$ & $9 \pm 4$ & 0.689 \\
\hline Time $<3.5 \mathrm{mmol} / \mathrm{L}$ during the 2 ed week (\%) & $6 \pm 2$ & $4 \pm 3$ & 0.092 \\
\hline Ketonuria positive during the 1st week (\%) & $55 \pm 7$ & $52 \pm 6$ & 0.698 \\
\hline Ketonuria positive during the 2ed week (\%) & $54 \pm 5$ & $42 \pm 5$ & $<0.001$ \\
\hline
\end{tabular}

GA glycated albumin

weeks $(14.6 \pm 2.2$ vs. $16.8 \pm 2.7, \mathrm{p}<0.001)$. In the trial, the women in the isCGM group spent increased time in the recommended glucose control target range of $3.5-7.8 \mathrm{mmol} / \mathrm{L}$ and reduced time above target compared with those in the control group at 2 weeks. There was no significant difference between the two groups in baseline level and time less than the target value after 2 weeks. In the second week of the study, the positive rate of urinary ketone body in isCGM group was significantly lower than that in control group $(42 \pm 5$ vs. $54 \pm 5, \mathrm{p}<0.001)$ (see Table 2$)$.

\section{Comparison of cases with maximum and minimum blood sugar values}

In the control group, the minimum blood sugar values of $40.0 \%(24 / 60)$ cases appeared within the $30 \mathrm{~min}$ before lunch, $23.3 \%(14 / 60)$ within the $30 \mathrm{~min}$ before breakfast, and $11.7 \%(7 / 60)$ within the $30 \mathrm{~min}$ before dinner. The cases of minimum at night only accounted for $8.3 \%$. Most of the maximum blood sugar appeared $2 \mathrm{~h}$ after three meals, totally accounting for $91.6 \%$ (55/60) of all cases. In isCGM group, the minimum blood sugar of $31.2 \%(20 / 64)$ cases appeared during 0:00-2:59 at night, $26.6 \%(17 / 64)$ cases appeared during 3:00-5:59 at night, and12.5\% (8/64) cases appeared during 9:00-11:59 and 15:00-17:59. The maximum blood sugar of 40.6\% (26/64)

Table 3 Comparison of cases with maximum and minimum blood sugar values of the study groups

\begin{tabular}{|c|c|c|c|}
\hline \multicolumn{2}{|l|}{ Control group $(n=60)$} & \multicolumn{2}{|l|}{ isCGM group $(n=64)$} \\
\hline Minimum values at 0 clock, n (\%) & $5(8.3)$ & Minimum values during 0:00-2:59, $\mathrm{n}(\%)$ & $20(31.2)$ \\
\hline Maximum values at 0 clock, $n(\%)$ & $3(5.0)$ & Maximum values during 0:00-2:59, n (\%) & $0(0)$ \\
\hline Minimum values before breakfast, $n(\%)$ & $14(23.3)$ & Minimum values during 3:00-5:59, n (\%) & $17(26.6)$ \\
\hline Maximum values before breakfast, $\mathrm{n}(\%)$ & $0(0)$ & Maximum values during 3:00-5:59, n (\%) & $0(0)$ \\
\hline Minimum values after breakfast, $n(\%)$ & $2(3.3)$ & Minimum values during 6:00-8:59, n (\%) & $2(3.12)$ \\
\hline Maximum values after breakfast, $\mathrm{n}(\%)$ & $14(23.3)$ & Maximum values during 6:00-8:59, n (\%) & $26(40.6)$ \\
\hline Minimum values before lunch, $\mathrm{n}(\%)$ & $24(40.0)$ & Minimum values during 9:00-11:59, n (\%) & $8(12.5)$ \\
\hline Maximum values before lunch, $n(\%)$ & $0(0)$ & Maximum values during 9:00-11:59, $\mathrm{n}(\%)$ & $12(18.7)$ \\
\hline Minimum values after lunch, $\mathrm{n}(\%)$ & $2(3.3)$ & Minimum values during 12:00-14:59, n (\%) & $3(4.68)$ \\
\hline Maximum values after lunch, $\mathrm{n}(\%)$ & $24(40)$ & Maximum values during 12:00-14:59, n (\%) & $7(11.0)$ \\
\hline Minimum values before dinner, $\mathrm{n}(\%)$ & $7(11.7)$ & Minimum values during 15:00-17:59, n (\%) & $8(12.5)$ \\
\hline Maximum values before dinner, $\mathrm{n}(\%)$ & $0(0)$ & Maximum values during 15:00-17:59, n (\%) & $12(18.7)$ \\
\hline Minimum values after dinner, $\mathrm{n}(\%)$ & $1(1.7)$ & Minimum values during 18:00-20:59, n (\%) & $3(4.68)$ \\
\hline Maximum values after dinner, $\mathrm{n}(\%)$ & $17(28.3)$ & Maximum values during 18:00-20:59, n (\%) & $7(11.0)$ \\
\hline Minimum values before sleeping, $n$ (\%) & $5(8.3)$ & Minimum values during 21:00-23:59, n (\%) & $3(4.68)$ \\
\hline Maximum values before sleeping, n (\%) & $2(3.3)$ & Maximum values during 21:00-23:59, n (\%) & $0(0)$ \\
\hline
\end{tabular}


patients appeared at 6:00-8:59. Except for the periods of 21:00-23:59, 0:00-2:59 and 3:00-5:59, where no maximum blood sugar appear, the maximum blood sugar was averagely distributed in other periods (see Table 3 ).

\section{Discussion}

With improved understanding in the pathogenesis of diabetes mellitus, more attention is now being paid to the effects of fetal malnourishment (due to obesity during pregnancy, excess nutrition and gestational diabetes mellitus, etc.) on the fetus during pregnancy. Early pregnancy is a critical period for fetal growth and development. The "fetal origin" hypothesis for diabetes mellitus proposed by David Barker [10] suggests that a poor developmental environment during pregnancy could significantly increase the risk of a number of chronic metabolic diseases such as diabetes mellitus, obesity and cardiovascular disease (CVD) in adulthood.

Murphy et al. study [11] shows that hyperglycemia in pregnancy leads to an increased risk of adverse outcomes, including fetal hyperinsulinemia, which leads to accelerated fetal growth and development, causing macrosomia. This increases the risk of complications in childbirth, including shoulder dystocia and birth trauma. Additionally, insulin resistance during pregnancy causes significant fluctuation in blood glucose levels in the mother, which is also related to many adverse pregnancy outcomes [12,13], Clearly, adequate blood glucose monitoring and maintenance during pregnancy is essential, particularly for mothers with DM $[14,15]$.

Common measures of blood glucose used in clinical practice are SMBG and hemoglobin A1c (HbAlc). SMBG can capture the blood glucose changes before meals, after meals, and at midnight for the course of 1 day, whereas HbAlc can estimate the average blood glucose level over the past 6-8 weeks. However, neither of these methods capture the dynamic changes of blood sugar throughout the day. The intermittently scanned CGM monitoring system can provide not only the current blood glucose value, but also the trend of blood glucose changes over the next $15 \mathrm{~min}$. Users can achieve targeted treatment according to the blood glucose value and trend values. Additionally, the device will analyze and process the collected data, such as the blood glucose compliance rate, the frequency of hypoglycemia in each period, the average blood glucose in each period, and the average blood glucose during the working time of the sensor. These data can be exported by computer and be used to generate reports [16].

Denice et al. study [17] suggests that use of CGM during pregnancy is associated with improved neonatal outcomes, possibly due to reduced exposure of the fetus to maternal hyperglycemia. Our study obtained similar results to this, suggesting that continuous glucose monitoring can reduce the exposure to of the fetus to maternal hyperglycemia. The value of GA was lower in the CGM group compared to the control group at 2ed weeks $(14.6 \pm 2.2$ vs. $16.8 \pm 2.7, \mathrm{p}<0.001)$. The women in the CGM group spent increased time in the recommended glucose control target range of $3.5-7.8 \mathrm{mmol} / \mathrm{L}$ and reduced time above target compared with those in the control group at 2 weeks.

A large amount of fat in the body is mobilized to provide energy in pregnant patients with diabetes mellitus due to insulin deficiency and impaired blood glucose utilization, leading to increased ketones in the body. Ketonuria results when the increase in ketone body volume exceeds the tissue utilization capacity $[18,19]$. In recent years, studies have found that the abnormal ketone body levels in pregnant women have a correlation with fetal malformation. Specifically, the accumulation of ketone bodies in pregnant women has adverse effects on the development of the fetal brain and nerves [20]. Therefore, it is important to detect the abnormal ketone body metabolism and act to correct the issue as early as possible. In our study, the number of "urine ketone body positive" patients in the isCGM group at week 2 was less than that in the control group. Quite possibly this is related to the reduction of hyperglycemia exposure to the fetus in pregnant women with isCGM. Hyperglycemic mothers should quickly take action to correct future hyperglycemia to avoid the fluctuation of blood glucose and subsequently avoid adverse effects on the baby.

Traditional methods are unable to fully assess patients' blood glucose level, which may lead to wrong assessment of blood glucose and improper clinical treatment. Compared with traditional monitoring methods, isCGM can predict and adapt to the dynamic changes of patients' blood glucose throughout the day [21, 22]. Through the study of different monitoring methods, we found that compared with traditional SMBG monitoring methods, the lowest blood glucose in isCGM group patients mainly appeared at 0:00-5:59, suggesting that low blood glucose is more common at night. Using SMBG to monitor blood glucose found that the minimum blood glucose was mainly distributed before meals, and only $8.3 \%$ of the minimum blood glucose was at nighttime. This indicated that the presence of night low blood glucose could not be detected by SMBG alone. IsCGM monitoring of blood glucose can more accurately decipher hypoglycemia at night and hyperglycemia after breakfast, which can guide clinical medication to better control blood glucose and consequently reduce the occurrence of adverse pregnancy outcomes related to hyperglycemia.

Our study also has its limitations. First, the study time was limited, and there was a lack of long-term follow-up. 
Second, the level of blood ketones was not detected in our study, only urine ketones, and there are many other influencing factors on urine ketone body formation. Finally, we observed that women in the CGM group had more unplanned exposure than those in the control group, as patients often encountered problems when using CGM, which increased the contact between patients and medical staff than SMGB group. Third, Abbott's FreeStyle Libre Flash Glucose Monitoring System is a limited precision in low glucose range. Hence, blood glucose below $4.0 \mathrm{mmol} / \mathrm{L}$ must be double-checked and confirmed by a glucometer.

\section{Conclusions}

In conclusion, intermittently scanned CGM can comprehensively and dynamically evaluate blood glucose changes in real time. In our study, isCGM reduced the exposure of pregnant women to hyperglycemia, thus reduced the exposure of the fetus to hyperglycemia, and reduced the production of urinary ketone bodies. It was better at detecting nocturnal hypoglycemia.

\section{Abbreviations}

isCGM: Intermittently scanned continuous glucose monitoring; SMBG: Self-monitoring of blood glucose; BMI: Body mass index; GDM: Gestational diabetes mellitus; PGDM: Pregestational diabetes mellitus; CVD: Cardiovascular disease; ART: Assisted reproductive technology; GA: Glycated albumin.

\section{Acknowledgements}

We thank the participants for participating in the study and the medical staff for collecting information and blood sample.

\section{Authors' contributions}

All the authors contributed significantly to the manuscript. SL analyzed and interpreted the data, and drafted the manuscript. HG significantly revised the draft, interpreted the data, and involved in data analyses. YZ and LS conducted the study, collected the information and participated in data interpretation. $\mathrm{PZ}, \mathrm{PL}$ and $\mathrm{JL}$ involved in the sample test, data management and draft revision. $\mathrm{LC}$ is the $\mathrm{PI}$ of project, who designed the study and critically revised the manuscript. All authors read and approved the final manuscript.

\section{Funding}

This work was supported by the National Natural Science Foundation of China (No. 81470187), Natural Science Foundation of Tianjin (No. 15ZXHLSY00460). Science and Technology Project of Tianjin (No.18ZXZNSY00280). Tianjin Health Commission Science and Technology Talent Cultivation Project (KJ20022).

\section{Availability of data and materials}

All data are freely available for scientific purpose.

\section{Declarations}

\section{Ethics approval and consent to participate}

The study was approved by the Ethics Committee of Chu Hsien-I Memorial Hospital of Tianjin Medical University (No. DXBYYhMEC2016-21) and that it conforms to the provisions of the Declaration of Helsinki (as revised in Fortaleza, Brazil, October 2013).

\section{Consent to publish}

All authors of the manuscript have read and agreed to its content and are accountable for all aspects of the accuracy and integrity of the manuscript.
Submitted article is original, it has not already been published in other journal, and is not currently under consideration by another journal.

\section{Competing interests}

The authors declare that they have no competing interests.

\section{Author details}

${ }^{1}$ Department of Endocrinology, Tianjin Xiqing Hospital, Tianjin, China. ${ }^{2} \mathrm{NHC}$ Key Laboratory of Hormones and Development (Tianjin Medical University), Tianjin Key Laboratory of Metabolic Diseases, Tianjin Medical University Chu Hsien-I Memorial Hospital \& Tianjin Institute of Endocrinology, Tianjin 300134, China.

Received: 1 November 2020 Accepted: 25 March 2021

Published online: 09 April 2021

\section{References}

1. Khadra D, Itani L, Tannir H, Kreidieh D, El Masri D, El Ghoch M. Association between sarcopenic obesity and higher risk of type 2 diabetes in adults: a systematic review and meta-analysis. World J Diabetes. 2019;10(5):311-23.

2. Federation ID. IDF diabetes atlas-8th edition [EB/OL]. 2017. http://www. diabetesatlas.org. Accessed 11 Aug 2018.

3. Zhu WW, Yang HX, Wei YM, Yan J, Wang ZL, Li XL, et al. Evaluation of the value of fasting plasma glucose in the first prenatal visit to diagnose gestational diabetes mellitus in china. Diabetes Care. 2013;36(3):586-90.

4. DeSisto CL, Kim SY, Sharma AJ. Prevalence estimates of gestational diabetes mellitus in the United States. Pregnancy risk assessment monitoring system (PRAMS) 2007-2010. Prev Chronic Dis. 2014;11:E104.

5. Nguyen CL, Pham NM, Binns CW, Duong DV, Lee AH. Prevalence of gestational diabetes mellitus in eastern and southeastern Asia: a systematic review and meta-analysis. J Diabetes Res. 2018;6536974:1-10.

6. Guariguata L, Linnenkamp U, Beagley J, Whiting DR, Cho NH. Global estimates of the prevalence of hyperglycaemia in pregnancy. Diatetes Res Clin Pract. 2014;103(2):176-85.

7. Massa GG, Gys I, Bevilacqua E, Wijnands A, Zeevaert R. Comparison of flash glucose monitoring with real time continuous glucose monitoring in children and adolescents with type 1 diabetes treated with continuous subcutaneous insulin infusion. Diabetes Res Clin Pract. 2019;152:111-8.

8. El-Laboudi AH, Godsland IF, Johnston DG, Oliver NS. Measures of glycemic variability in type 1 diabetes and the effect of real-time continuous glucose monitoring. Diabetes Technol Ther. 2016;18(12):806-12.

9. Lucidi P, Porcellati F, Bolli GB, Fanelli CG. Real-time continuous glucose monitoring decreases the risk of severe hypoglycemia in people with type 1 diabetes and impaired awareness of hypoglycemia. Ann Transl Med. 2018;6(Suppl 2):S97.

10. Cooper C, Phillips D, Osmond C, Fall C, Eriksson J. David James Purslove Barker: clinician, scientist and father of the 'fetal origins hypothesis.' J Dev Orig Health Dis. 2014;5(3):161-3.

11. Murphy HR, Bell R, Cartwright C, Curnow P, Maresh M, Morgan M, et al. Improved pregnancy outcomes in women with type 1 and type 2 diabetes but substantial clinic-to-clinic variations: a prospective nationwide study. Diabetologia. 2017;60(9):1668-77.

12. Ding T-T, Xiang J, Luo B-R, Hu J. Relationship between the IADPSGcriteria-defined abnormal glucose values and adverse pregnancy outcomes among women having gestational diabetes mellitus. Medicine. 2018;97(43):e12920.

13. Martino J, Sebert S, Segura MT, García-Valdés L, Florido J, Padilla MC, et al. Maternal body weight and gestational diabetes differentially influence placental and pregnancy outcomes. J Clin Endocrinol Metab. 2016;101(1):59-68.

14. Russo GT, Scavini M, Acmet E, Bonizzoni E, Bosi E, Giorgino F, et al. The burden of structured self-monitoring of blood glucose on diabetesspecific quality of life and locus of control in patients with noninsulintreated type 2 diabetes: the prisma study. Diabetes Technol Ther. 2016;18(7):421-8.

15. Young LA, Buse JB, Weaver MA, Vu MB, Mitchell CM, Blakeney T, et al. Glucose self-monitoring in non-insulin-treated patients with type 2 
diabetes in primary care settings: a randomized trial. JAMA Intern Med. 2017;177(7):920-9.

16. Wadwa RP, Laffel LM, Shah VN, Garg SK. Accuracy of a factory-calibrated, real-time continuous glucose monitoring system during 10 days of use in youth and adults with diabetes. Diabetes Technol Ther. 2018;20(6):395-402.

17. Feig DS, Donovan LE, Corcoy R, Murphy KE, Amiel SA, Hunt KF, et al. Continuous glucose monitoring in pregnant women with type 1 diabetes (CONCEPTT): a multicentre international randomised controlled trial. Lancet. 2017;390(10110):2347-59.

18. Spanou L, Dalakleidi K, Zarkogianni K, Papadimitriou A, Nikita K, Vasileiou $\checkmark$, et al. Ketonemia and ketonuria in gestational diabetes mellitus. Hormones. 2015;14(4):644-50.

19. Luethi N, Cioccari L, Crisman M, Bellomo R, Eastwood GM, Mårtensson J. Prevalence of ketosis, ketonuria, and ketoacidosis during liberal glycemic control in critically ill patients with diabetes: an observational study. Crit Care. 2016;20:297.
20. Camberos-Luna L, Geronimo-Olvera C, Montiel T, Rincon-Heredia R, Massieu L. The ketone body, b-hydroxybutyrate stimulates the autophagic flux and prevents neuronal death induced by glucose deprivation in cortical cultured neurons. Neurochem Res. 2015;41(3):600-9.

21. Secher AL, Ringholm L, Andersen HU, Damm P, Mathiesen ER. The effect of real-time continuous glucose monitoring in pregnant women with diabetes: a randomized controlled trial. Diabetes Care. 2013;36(7):1877-83.

22. Voormolen DN, DeVries JH, Sanson RME, Heringa MP, de Valk HW, Kok M, et al. Continuous glucose monitoring during diabetic pregnancy (GlucoMOMS): a multicentre randomized controlled trial. Diabetes Obes Metab. 2018;20(8):1894-902.

\section{Publisher's Note}

Springer Nature remains neutral with regard to jurisdictional claims in published maps and institutional affiliations.
Ready to submit your research? Choose BMC and benefit from:

- fast, convenient online submission

- thorough peer review by experienced researchers in your field

- rapid publication on acceptance

- support for research data, including large and complex data types

- gold Open Access which fosters wider collaboration and increased citations

- maximum visibility for your research: over $100 \mathrm{M}$ website views per year

At BMC, research is always in progress.

Learn more biomedcentral.com/submissions 